\title{
The position of combined medical treatment in acromegaly
}

Eva C. Coopmans ${ }^{*}$

https://orcid.org/0000-0003-4780-2468

Sebastiaan W. F. van Meyel ${ }^{1 *}$

https://orcid.org/0000-0002-1148-9863

Aart J. van der Lely'

http://orcid.org/0000-0002-1059-0126

Sebastian J. C. M. M. Neggers'
${ }^{1}$ Department of Medicine, Section Endocrinology, Pituitary Center Rotterdam, Erasmus University Medical Center Rotterdam, Rotterdam, The Netherlands

* Both authors equally contributed to this study

Correspondence to:

Eva C. Coopmans

Erasmus University Medical

Center Rotterdam

PO Box 2040

3000 CA Rotterdam

The Netherlands

e.coopmans@erasmusmc.nl

Received on Oct/3/2019

Accepted on Nov/19/2019

DOI: 10.20945/2359-3997000000195

\section{INTRODUCTION}

A cromegaly is a rare disorder predominantly caused by a growth hormone $(\mathrm{GH})$-secreting pituitary adenoma, consequently resulting in elevated secretion of insulin-like growth factor-1 (IGF-1) (1). If untreated, acromegaly leads to disadvantageous metabolic changes and comorbidities, such as hypertension, cardiovascular diseases, diabetes mellitus, respiratory system dysfunction and in particular malignant neoplasms (2-4). There are multiple treatment modalities for acromegaly and the current consensus on the treatment goals include normalization of IGF-1 levels, reduction of GH levels below $1.0 \mathrm{ug} / \mathrm{L}$, decrease of tumour volume, and improvement of clinical signs and symptoms $(5,6)$. Depending on patient characteristics and tumour size the possibilities range from surgery, medical treatment or radiotherapy. Treatment of acromegaly is complex and most cases require a stepwise, multidisciplinary approach to control the disease.

Transsphenoidal surgery (TSS) remains the primary treatment modality in most patients with acromegaly $(5,7,8)$, especially in those harbouring a microadenoma or intrasellar macroadenoma $(9,10)$. Surgery is effective in the management of acromegaly and in experienced centers biochemical remission rates up to $80 \%$ can be achieved. However, the vast majority of patients have macroadenomas, often with suprasellar extension. In these cases, the postoperative remission rates are much lower (11). Therefore, in patients for whom surgery is contra-indicated, in whom prefer pharmacological treatment, or in whom postoperative remission is not achieved, additional treatment is needed. This is primarily in the form of medical treatment with radiotherapy generally reserved as a third-line treatment option $(7,12)$.

The medical treatment options are as follows: dopamine agonists (e.g., cabergoline), first-generation long-acting somatostatin receptor ligands (SRLs), the $\mathrm{GH}$ receptor antagonist pegvisomant (PEGV) and the second-generation somatostatin multi-receptor ligand pasireotide long-acting release (PAS-LAR). Despite significant medical and surgical advances, many acromegaly patients are not adequately controlled. For these patients advances in combination medical treatment offer new perspectives. The outcomes of combination medical treatment may reflect both additive and synergistic effects. This review aims to discuss the current position of combined medical treatment options in acromegaly. The proposed position of combined medical treatment in acromegaly presented in this review are based on clinical studies evaluating the efficacy and safety of combined medical treatment(s) and our own experiences with combination therapy. 


\section{WHAT IS THE EFFICACY OF COMBINATION THERAPY?}

First-line medical treatment according to the recently published consensus criteria of Melmed and colleagues (6) remains first-generation SRLs monotherapy with lanreotide Autogel (ATG) or octreotide long-acting repeatable (LAR). SRLs act mainly on the somatostatin receptor subtype $2 \mathrm{a}\left(\mathrm{SST}_{2 \mathrm{a}}\right)$ to inhibit $\mathrm{GH}$ secretion and normalize both GH and IGF-1 levels with an efficacy rate of about $25 \%-45 \%$ (13-17). If biochemical control is not achieved after administering the maximal dose of firstgeneration SRLs, the consensus criteria (6) recommend that treatment should be individualized based on the presence or absence of clinically relevant residual tumour and impaired glucose tolerance. Dopamine agonists monotherapy (e.g., cabergoline), which are acting on dopamine 2 receptors, can be considered as first-line medical therapy postsurgery only for patients with modestly elevated GH and IGF-1 levels (IGF-1 $<2.5 \mathrm{x}$ upper limit of normal (ULN) $(6,7,18,19)$.

There are multiple options for second-line therapy as recommended by the consensus criteria (6): PAS-LAR monotherapy or PEGV combined with or substituted for first-generation SRLs. PEGV monotherapy has a reported efficacy rate up to $89 \%$ (20). Similarly, PEGV in combination with first-generation SRL has the ability to normalize IGF-1 levels in the majority of patients, provided that the appropriate dose has been applied. According to the consensus criteria, PEGV substituted for or combined with first-generation SRL therapy is recommended for patients with no significant response ( $<20 \%$ IGF-1 reduction) during first-generation SRLs monotherapy (6). However, we recommend that combination therapy with first-generation SRL and PEGV is the best choice as second-line option in all non-responders (defined as IGF-1 $>1.3 \times$ ULN) by using the following arguments (21):

1. The potential advantage of combination therapy is that a lower PEGV dosage is needed to normalize IGF-1 levels compared with monotherapy of PEGV, leading to a reduction in injection frequency for patients (22-24).

2. There are indications that combination therapy might have a favourable effect on quality of life (QoL) compared to first-generation SRLs monotherapy, including the ones who are biochemically controlled (25).

3. Although monotherapy with PEGV does not reduce tumour size, combination therapy with first-generation SRL may result in tumour size control or even tumour shrinkage in most patients (23).

4. Headaches may be alleviated during combination therapy with PEGV and firstgeneration SRL. It is proposed that nociceptive peptides are inhibited by first-generation SRLs, making it the favourable treatment option for patients with headaches $(26,27)$.

Initiating combination therapy with first-generation SRLs and PEGV is not preferred in patients showing poor control of diabetes during first-generation SRLs monotherapy. In patients receiving first-generation SRLs with worsening of the glucose control, previous studies have shown that PEGV therapy had a more favourable effect on the glycaemic control (28-30). In those cases, PEGV monotherapy would be a more suitable option as it may improve glucose metabolism by reducing insulin resistance (28-30). This is more or less in accordance with the consensus criteria (6), that recommend patients with pre-existing clinically relevant impaired glucose metabolism should be switched from first-generation SRLs to PEGV monotherapy. In addition, in patients with no biochemical significant response $(<20 \%$ IGF-1 reduction) and without significant tumour shrinkage $(<25 \%$ tumour volume reduction) during first-generation SRLs monotherapy, PEGV monotherapy is recommended. The maintenance of first-generation SRLs has potentially no additional benefit and increased the risk of adverse events such as cholelitiasis.

The consensus criteria recommend the addition of cabergoline to continued first-generation SRLs treatment in a small proportion of patients with modestly elevated IGF-1 levels during SRL administration (6). This recommendation is based on a previous report that showed that IGF-1 normalization has been observed only in patients with modestly elevated IGF-1 levels (19). The exact mechanism how the combination therapy of cabergoline and first-generation SRL treatment imposes a synergistic effect on the suppression of GH is not known (3133). Proposed mechanism includes increased intestinal transit time (34), crosstalk of G-coupled receptors or dimerization on the cell (post-) membrane level (35) or paradoxical nonobligatory hetero-dimerization (36). Regarding the efficacy, in a meta-analysis consisting of 77 patients, up to $50 \%$ achieved normalized IGF-1 levels after adding cabergoline therapy (19). 
PEGV and cabergoline combination therapy may offer additional benefits to a select group of patients with slightly elevated IGF-1 levels during PEGV monotherapy. However, the use of this combination treatment does not appear to be exceptional in clinical practice, as $10 \%$ of acromegaly patients included in the ACROSTUDY (37) were using this combination therapy. A retrospective study investigated the efficacy of this combination therapy, and found that PEGV in combination with cabergoline normalized IGF-1 levels in 4 out of 14 acromegaly patients (28\%) and decreased IGF-1 levels in 9 out of 14 patients (64\%) (38). A significant response to this combination treatment was associated with baseline IGF-1 levels (IGF-1 < 1.6 $\mathrm{x}$ ULN), female gender, higher baseline prolactin concentrations and a lower body weight (38). A prospective study investigating PEGV and cabergoline mono- and combination therapy, showed that the combination of low-dose PEGV and cabergoline treatment resulted in $68 \%$ of patients in normalization of IGF-1 levels (39). Moreover, they suggest that this combination treatment is more effective in reducing IGF-1 levels than PEGV or cabergoline treatment alone (39). Co-administration of PEGV and cabergoline has several advantages over the PEGV and first-generation SRL combination treatment, as cabergoline is orally administered, less expensive than first-generation SRLs and overall well-tolerated.

The current consensus criteria (6) advocate PASLAR monotherapy as second-line treatment for patients without biochemical response to first-generation SRLs if a clinically relevant residual tumour that is unsuitable for resection is present. In accordance with the current consensus criteria (6), we hypothesize that in particular young patients (aged $<40$ years) with macroadenomas that show tumour growth during first-generation SRL monotherapy or PEGV [i.e., clinically aggressive tumours (40)], PAS-LAR monotherapy can be considered as a next treatment step before starting with radiotherapy (21). The same strategy can be applied for patients whose disease was previously not controlled by first-generation SRLs with tumour growth (i.e., reflecting the presence of more aggressive tumours) during PEGV monotherapy (21). In addition, we recommend to switch to PAS-LAR monotherapy as an alternative to PEGV monotherapy or combination therapy for patients with the following baseline clinical features $(21)$ :

1. Patients whose disease was previously not controlled by first-generation SRLs, who experience side-effects, or who are intolerant to PEGV monotherapy.

2. Patients with severe headaches not responsive to first-generation SRLs. Headaches may be alleviated during PAS-LAR treatment.

There is evidence that biochemical response to somatostatin analogues can be predicted by the SST receptor subtype binding profile in the adenoma tissue $(41,42)$. Whereas first-generation SRLs show a high preferential binding affinity for $\mathrm{SST}_{2 \mathrm{a}}$ receptor and PAS-LAR exhibits particularly high affinity for $\mathrm{SST}_{5}$ receptor (43). However, previous in vitro studies (4446) and one in vivo study (47) suggest that, overall, PAS-LAR exerts its anti-secretory activity mainly by the activation of $\mathrm{SST}_{2 \mathrm{a}}$ receptor. In the latter study, which include patients showing a partial response to first-generation SRLs, the IGF-1 lowering effects of PAS-LAR treatment correlated with the effect of SRL treatment (47). Therefore, both the clinical response to first-generation SRL treatment and $\mathrm{SST}_{2 \mathrm{a}}$ receptor expression on adenoma tissue could predict the biochemical response to PAS-LAR treatment.

The current consensus criteria (6) do not address the current position of PAS-LAR in combination with PEGV in the medical management of acromegaly since it was held before our data $(48,49)$ was published. Preferred baseline clinical features for the use of PASLAR in combination with PEGV would be patients without diabetes using low PEGV doses $(\leq 80 \mathrm{mg}$ / week) during combination therapy with first-generation SRLs (21). The PEGV dosages can be reduced or sometimes even discontinued due to the PEGV sparing effect of PAS-LAR (48). It should be stressed that it is likely that those patients end up with PAS-LAR monotherapy. Patients biochemically controlled during first-generation SRL and PEGV combination therapy, who use first-generation SRLs every three weeks or have symptoms of active acromegaly in the fourth week after first-generation SRL administration, may experience symptomatic improvement after switching to PAS-LAR and PEGV combination therapy (21). At last, we postulate that PAS-LAR treatment may improve tumour size control or even tumour shrinkage. Therefore, patients experiencing tumour growth during first-generation SRL and PEGV combination therapy could be switched to PAS-LAR and PEGV combination therapy (2l).

The safety of the different combined medical treatments will be addressed in the paragraph below 
where its effect on tumour size will be discussed separately from other side effects.

\section{COMBINATION THERAPY AND TUMOUR SIZE}

The prevention of further tumour growth and consequently tumour mass complications is an advantageous treatment outcome in acromegaly patients, as the existence of large tumours is associated with poor clinical outcomes (50). Clinical evidence has shown that first-generation SRL treatment exhibits anti-proliferative effects and induces tumour shrinkage in most patients $(16,51,52)$. Moreover, greater tumour shrinkage was observed in naïve patients and those treated with first-generation SRLs monotherapy for more than one year. In addition, dopamine agonists may exert anti-proliferative effects on pituitary tumour cells (53).

Detailed research on tumour shrinkage and combination therapy is rare. For example, in 158 patients the results of the biochemical efficacy of cabergoline and first-generation SRL combination therapy were available, however, information on tumour volumes is scarce, which could underestimate tumour shrinkage. However, in one study of 10 patients resistant to firstgeneration SRL therapy (54), total tumour shrinkage went from 34 to $2 \mathrm{l} \mathrm{uL}(\mathrm{p}=0.009)$ after the addition of cabergoline $(0.25-2 \mathrm{mg} /$ week) for a period of six months. For patients who are biochemically resistant to first-generation SRLs, the addition of cabergoline may be useful as SRLs could maintain long-term effects on tumour mass, while cabergoline may lower IGF-1 levels.

PEGV monotherapy does not have the ability to decrease tumour size. In the Italian ACROSTUDY patients, none of the 35 patients showed significant tumour growth under PEGV alone, whereas in one case, progressive shrinkage of the adenoma was documented by MRI, which was no longer detectable after six years of treatment (55). In the same study, among the 27 patients treated with PEGV in combination with firstgeneration SRL, a significant growth of the residual adenoma tissue occurred in one case. However, this patient was characterized by clinically aggressive disease (40) and, when the tumour enlargement was noted, was eventually treated with PEGV $40 \mathrm{mg}$ /day in combination with lanreotide ATG $120 \mathrm{mg} / \mathrm{month}$ (55). In the Dutch cohort among 141 patients treated with PEGV in combination with first-generation SRL, growth of the adenoma occurred in one case as well, while this growth was already observed before the addition of PEGV (23). In the report by Neggers and colleagues they assessed the long-term safety of the combined use of PEGV and first-generation SRL in a large group of $(\mathrm{n}=86)$ patients over a longer period of time (56). In 14 patients the size of the tumour significantly decreased more than $20 \%$, whereas tumour size increase was not observed (56). All in all, these data do suggest that PEGV does not cause significant increase in tumour size in acromegaly patients. Therefore, PEGV in combination with first-generation SRL should be considered as a safe approach, especially when first-generation SRLs still can reduce tumour size in PEGV treated subjects plus the fact that in a small number of SRL treated subjects, an increase in tumour size has been observed as well.

To our knowledge, there are no studies investigating the tumour response after long-term PAS-LAR alone or in combination with PEGV therapy, except for one. In this follow-up analysis of 47 patients from the PAPE study (49), which investigated patients who were either treated with PAS-LAR monotherapy or the combination of PAS-LAR and PEGV therapy, assessment of $\mathrm{Tl}$ and $\mathrm{T} 2$-weighted signal by MRI was performed. Surprisingly, the T2-weighted MRI signal of the adenoma was increased in $14(30 \%)$ of the 47 patients during PAS-LAR treatment (57). The increase in T2-signal was particularly substantial $(>50 \%)$ in eight patients, where the majority of the adenoma became T2-hyperintense. Generally speaking, a T2-hyperintense signal indicates cystic degeneration, tumour cell necrosis, or both, which is suggestive of an anti-tumour effect (57). Besides, they observed clinically significant $(\geq 25 \%)$ tumour shrinkage in 5 of the 14 patients with adenomas in which they observed increased T2-signal intensity during 9 months of PAS-LAR treatment. Up to 30 months of PAS-LAR treatment, an additional decrease in tumour volume was observed in the adenomas of five patients (mean tumour volume was $2.9 \mathrm{~cm}^{3}$ at baseline, $2.3 \mathrm{~cm}^{3}$ after 9 months of PAS-LAR, and $1.9 \mathrm{~cm}^{3}$ after about 30 months) (58).

Antitumour effects of somatostatin receptor ligands have not been reported over the last 30 years. If PAS-LAR could induce cystic degeneration, tumour cell necrosis, or both, it might affect the clinical management of acromegaly. Preoperative treatment with PAS-LAR, for example, might induce (partial) 
cystic degeneration, tumour cell necrosis, or both, which could improve surgical outcomes. This potential antitumour effect of PAS-LAR might reduce disease activity and even alleviate symptoms, or detrimentally may induce anterior pituitary deficiencies. Therefore, close monitoring of pituitary tumour status is advised when using PAS-LAR therapy alone or in combination with PEGV.

\section{SAFETY AND QUALITY OF LIFE}

First-generation SRLs are generally well tolerated, usually with transient mild side effects. Most patients experience nausea, diarrhoea, gastro-intestinal related complaints and abdominal pain or distension. More severe adverse effects may include hair loss, cholelithiasis and bradycardia $(13,16)$. In general, the net effect of first-generation SRLs on glucose metabolism is considered marginal. Recently, in a large meta-analysis of 47 prospective interventional trials, they studied in 1,297 patients the effect of first-generation SRLs on glucose homeostasis (59). The authors show that firstgeneration SRLs significantly reduce insulin secretion, and this was not (completely) counterbalanced by the reduction in IGF-1 and GH levels. Therefore, the net effect of SRLs on glucose metabolism may be clinically relevant, because most patients are already insulin resistant and have prediabetes irrespective of the biochemical control.

Regarding the safety aspects of PEGV monotherapy or in combination with first-generation SRLs, in a recent update of the ACROSTUDY (60), hepatobiliary-related side effects were found for up to $10 \%$ of 2,090 patients, from which $4 \%$ are considered related to treatment. From the total of 1,094 patients, $62 \%$ remained to have normal transaminase (TA) values during follow-up. There was a reported level of $3 \%$ increases in TAs $>3$ $x$ ULN. A total of 89 patients entered the study with elevated TAs between 1-3 x ULN, from this 34\% drifted downwards to normal TA values during follow-up with PEGV treatment, 46\% remained within their baseline range and $10 \%$ had TAs > $3 \times$ ULN. Lipodystrophy at the injection site of PEGV has been reported, which regressed in most patients after frequent rotation or after discontinuation of PEGV (61). In a subgroup of patients, the combination therapy of first-generation SRL and PEGV has favourable effects on QoL compared with first-generation SRL monotherapy, including the patients whose disease is biochemically controlled (25).
Furthermore, an advantage of this combination therapy is that first-generation SRLs are typically effective in resolving headaches due to inhibition of nociceptive peptides, making it the preferred treatment for patients with headaches $(26,27)$.

The adverse effects of the combination therapy of first-generation SRL and cabergoline include: nausea, headache, dizziness and hypotension (19). High cabergoline dosages used in Parkinson's patients have valvulopathy as a known side effect (62). Lower dosages and/or short-term use of dopamine agonists have not been proven to induce valvulopathy in acromegaly patients (63). Such outcomes of long-term cabergoline and first-generation SRL combination therapy in acromegaly patients is not known.

PAS-LAR monotherapy has a negative effect on glucose metabolism. It suppresses insulin secretion and incretin response, resulting in a higher frequency of hyperglycaemia and diabetes $(13,49)$. In two studies comparing first-generation SRL with PAS-LAR monotherapy, hyperglycaemia-related adverse events were described in 22-30\% with first-generation SRLs and in $57 \%-65 \%$ of patients treated with PAS-LAR therapy $(13,14)$. In the PAPE study, the frequency of diabetes mellitus doubled from $33 \%$ at baseline to $69 \%$ at 24 weeks and increased further to $77 \%$ at 48 weeks (48). The pathophysiology of hyperglycaemia appears to be due to a combination of insulin and incretin suppressive effects of PAS-LAR (64). However, the precise mechanism of how PAS-LAR causes hyperglycaemia is not well understood. In biochemically controlled patients during first-generation SRL and PEGV combination therapy, who are still experiencing symptoms of active acromegaly in the fourth week after administration of first-generation SRLs, could experience symptomatic improvement after switching to PAS-LAR and PEGV combination therapy.

\section{CONCLUSION}

The desired treatment approach in acromegaly patients should take all the individual traits of the disease into consideration, such as: GH and IGF-1 levels, tumour size, acromegaly symptoms, comorbidities, costs, QoL and patient preferences. Although surgery remains the mainstay treatment, new medical combination therapies have offer new perspectives for acromegaly patients with persistent disease activity despite surgery and/ or medical monotherapies. And with the introduction 
of new effective drugs, the medical therapies may be more suitable for certain types of patients. It is of importance to monitor medical therapies closely as it is crucial in controlling the disease. We elucidated that the use of combination therapies could provide sufficient biochemical or tumour control in patients uncontrolled under first-generation SRL monotherapy. Every medical combination therapy carries along benefits and drawbacks. In the end, the real challenge for the clinician is to decide in each individual patient whether one outweigh other treatment options.

Disclosure: AJvdL is a consultant for Pfizer, and has received speaker fees from Novartis, Ipsen, and Pfizer. SJCMMN has received research grants and speaker fees from Ipsen, Novartis, and Pfizer, and consulting fees from Ipsen. ECC and SWFM have nothing to disclose.

\section{REFERENCES}

1. Melmed S. Acromegaly pathogenesis and treatment. J Clin Invest; 2009;119(11):3189-202.

2. Colao A, Ferone D, Marzullo P, Lombardi G. Systemic complications of acromegaly: epidemiology, pathogenesis, and management. Endocrine Rev. 2004;25(1):102-52.

3. Melmed S. Medical progress: acromegaly. N Engl J Med. 2006;355(24):2558-73.

4. Dekkers OM, Biermasz NR, Pereira AM, Romijn JA, Vandenbroucke JP. Mortality in acromegaly: a metaanalysis. J Clin Endocrinol Metab. 2008;93(1):61-7.

5. Katznelson L, Laws ER Jr, Melmed S, Molitch ME, Murad MH, Utz A, et al. Acromegaly: an endocrine society clinical practice guideline. J Clin Endocrinol Metab. 2014;99(11):3933-51.

6. Melmed S, Bronstein MD, Chanson P, Klibanski A, Casanueva FF, Wass JAH, et al. A Consensus Statement on acromegaly therapeutic outcomes. Nat Rev Endocrinol. 2018;14(9):552-61.

7. Katznelson L, Atkinson JL, Cook DM, Ezzat SZ, Hamrahian AH, Miller KK; American Association of Clinical Endocrinologists. American Association of Clinical Endocrinologists medical guidelines for clinical practice for the diagnosis and treatment of acromegaly - 2011 update. Endocr Pract. 2011;17 Suppl 4:1-44.

8. Giustina A, Chanson P, Kleinberg D, Bronstein MD, Clemmons DR, Klibanski A, et al.; Acromegaly Consensus Group. Expert consensus document: A consensus on the medical treatment of acromegaly. Nat Rev Endocrinol. 2014;10(4):243-8.

9. Fahlbusch R, Honegger J, Buchfelder M. Surgical management of acromegaly. Endocrinol Metab Clin North Am. 1992;21(3):669-92.

10. Ross DA, Wilson CB. Results of transsphenoidal microsurgery for growth hormone-secreting pituitary adenoma in a series of 214 patients. J Neurosurg. 1988;68(6):854-67.

11. Clayton RN, Stewart PM, Shalet SM, Wass JA. Pituitary surgery for acromegaly. Should be done by specialists. BMJ. 1999;319(7210):588-9.

12. Hannon MJ, Barkan AL, Drake WM. The role of radiotherapy in acromegaly. Neuroendocrinology. 2016;103(1):42-9.

13. Colao A, Bronstein MD, Freda P, Shen CC, Gadelha M, Fleseriu M, et al. Pasireotide versus octreotide in acromegaly: a head-to-head superiority study. J Clin Endocrinol Metab. 2014;99(3):791-9.

14. Melmed S, Cook D, Schopohl J, Goth MI, Lam KS, Marek J. Rapid and sustained reduction of serum growth hormone and insulin-like growth factor- 1 in patients with acromegaly receiving lanreotide Autogel therapy: a randomized, placebo-controlled, multicenter study with a 52 week open extension. Pituitary. 2010;13(1):18-28.

15. Murray RD, Melmed S. A critical analysis of clinically available somatostatin analog formulations for therapy of acromegaly. $J$ Clin Endocrinol Metab. 2008;93(8):2957-68.

16. Mercado M, Borges F, Bouterfa H, Chang TC, Chervin A, Farrall AJ, et al.; SMS995B2401 Study Group. A prospective, multicentre study to investigate the efficacy, safety and tolerability of octreotide LAR (long-acting repeatable octreotide) in the primary therapy of patients with acromegaly. Clin Endocrinol (Oxf). 2007;66(6):859-68.

17. Caron PJ, Bevan JS, Petersenn S, et al. Tumor Shrinkage With Lanreotide Autogel $120 \mathrm{mg}$ as Primary Therapy in Acromegaly: Results of a Prospective Multicenter Clinical Trial. The Journal of Clinical Endocrinology \& Metabolism 2014; 99(4): 1282-90.

18. Diez JJ, Iglesias P. Current management of acromegaly. Expert Opin Pharmacother. 2000;1(5):991-1006.

19. Sandret L, Maison P, Chanson P. Place of cabergoline in acromegaly: a meta-analysis. J Clin Endocrinol Metab. 2011;96(5):1327-35.

20. Trainer PJ, Drake WM, Katznelson L, Freda PU, Herman-Bonert V, van der Lely AJ, et al. Treatment of acromegaly with the growth hormone-receptor antagonist pegvisomant. $N$ Engl J Med. 2000;342(16):1171-7.

21. Coopmans EC, Muhammad A, van der Lely AJ, Janssen J, Neggers S. How to Position Pasireotide LAR Treatment in Acromegaly. J Clin Endocrinol Metab. 2019;104(6):1978-88.

22. Neggers SJ, van der Lely AJ. Combination treatment with somatostatin analogues and pegvisomant in acromegaly. Growth Horm IGF Res. 2011;21(3):129-33.

23. Neggers SJ, Franck SE, de Rooij FW, Dallenga AH, Poublon RM, Feelders RA, et al. Long-term efficacy and safety of pegvisomant in combination with long-acting somatostatin analogs in acromegaly. J Clin Endocrinol Metab. 2014;99(10):3644-52.

24. Trainer PJ, Ezzat S, D'Souza GA, Layton G, Strasburger CJ. A randomized, controlled, multicentre trial comparing pegvisomant alone with combination therapy of pegvisomant and long-acting octreotide in patients with acromegaly. Clin Endocrinol (Oxf). 2009;71(4):549-57.

25. Neggers SJ, van Aken MO, de Herder WW, Feelders RA, Janssen JA, Badia X, et al. Quality of life in acromegalic patients during long-term somatostatin analog treatment with and without pegvisomant. J Clin Endocrinol Metab. 2008;93(10):3853-9.

26. Levy MJ, Matharu M, Goadsby PJ. Chronic headache and pituitary tumors. Curr Pain Headache Rep. 2008;12(1):74-8.

27. Lin TH, Hu K, Flarakos J, Sharr-McMahon M, Mangold JB, He H, et al. Assessment of the absorption, metabolism and excretion of $\left[{ }^{14} \mathrm{C}\right]$ pasireotide in healthy volunteers using accelerator mass spectrometry. Cancer Chemother Pharmacol. 2013;72(1):181-8.

28. Ghigo E, Biller BM, Colao A, Kourides IA, Rajicic N, Hutson RK, et al. Comparison of pegvisomant and long-acting octreotide in patients with acromegaly naive to radiation and medical therapy. J Endocrinol Invest. 2009;32(11):924-33.

29. Barkan AL, Burman P, Clemmons DR, Drake WM, Gagel RF, Harris PE, et al. Glucose homeostasis and safety in patients with acromegaly converted from long-acting octreotide to pegvisomant. J Clin Endocrinol Metab. 2005;90(10):5684-91.

30. Drake WM, Rowles SV, Roberts ME, Fode FK, Besser GM, Monson $\mathrm{JP}$, et al. Insulin sensitivity and glucose tolerance improve in patients with acromegaly converted from depot octreotide to pegvisomant. Eur J Endocrinol. 2003;149(6):521-7.

31. Lamberts SW, Verleun T, Hofland L, Oosterom R. Differences in the interaction between dopamine and estradiol on prolactin 
release by cultured normal and tumorous human pituitary cells. J Clin Endocrinol Metab. 1986;63(6):1342-7.

32. Rocheville M, Lange DC, Kumar U, Patel SC, Patel RC, Patel YC. Receptors for dopamine and somatostatin: formation of hetero-oligomers with enhanced functional activity. Science. 2000;288(5463):154-7.

33. Lamberts SW, Zweens M, Verschoor L, del Pozo E. A comparison among the growth hormone-lowering effects in acromegaly of the somatostatin analog SMS 201-995, bromocriptine, and the combination of both drugs. J Clin Endocrinol Metab. 1986;63(1):16-9.

34. JalladRS, Bronstein MD. Optimizing medical therapy of acromegaly: beneficial effects of cabergoline in patients uncontrolled with longacting release octreotide. Neuroendocrinology. 2009;90(1):82-92.

35. Saveanu A, Jaquet P, Brue T, Barlier A. Relevance of coexpression of somatostatin and dopamine D2 receptors in pituitary adenomas. Mol Cell Endocrinol. 2008;286(1-2):206-13.

36. Bulenger S, Marullo S, Bouvier M. Emerging role of homo- and heterodimerization in G-protein-coupled receptor biosynthesis and maturation. Trends Pharmacol Sci. 2005;26(3):131-7.

37. Trainer PJ. ACROSTUDY: the first 5 years. Eur $\mathrm{J}$ Endocrinol. 2009;161 Suppl 1:S19-24.

38. Bernabeu I, Alvarez-Escola C, Paniagua AE, Lucas T, Pavón I, Cabezas-Agrícola JM, et al. Pegvisomant and cabergoline combination therapy in acromegaly. Pituitary. 2013;16(1):101-8.

39. Higham CE, Atkinson AB, Aylwin S, Bidlingmaier M, Drake WM, Lewis $A$, et al. Effective combination treatment with cabergoline and low-dose pegvisomant in active acromegaly: a prospective clinical trial. J Clin Endocrinol Metab. 2012;97(4):1187-93.

40. Besser GM, Burman P, Daly AF. Predictors and rates of treatmentresistant tumor growth in acromegaly. Eur $\mathrm{J}$ Endocrinol. 2005;153(2):187-93.

41. Gatto F, Feelders RA, van der Pas R, Kros JM, Waaijers M, SprijMooij $D$, et al. Immunoreactivity score using an anti-sst2A receptor monoclonal antibody strongly predicts the biochemical response to adjuvant treatment with somatostatin analogs in acromegaly. J Clin Endocrinol Metab. 2013;98(1):E66-71.

42. Casar-Borota O, Heck A, Schulz S, Nesland JM, Ramm-Pettersen J, LekvaT, et al. Expression of SSTR2a, but not of SSTRs 1, 3, or 5 in somatotroph adenomas assessed by monoclonal antibodies was reduced by octreotide and correlated with the acute and long-term effects of octreotide. J Clin Endocrinol Metab. 2013;98(11):E1730-9.

43. Schmid HA. Pasireotide (SOM230): development, mechanism of action and potential applications. Mol Cell Endocrinol. 2008;286(1-2):69-74.

44. Gatto F, Feelders RA, Franck SE, van Koetsveld PM, Dogan F, Kros JM, et al. In Vitro Head-to-Head Comparison Between Octreotide and Pasireotide in GH-Secreting Pituitary Adenomas. J Clin Endocrinol Metab. 2017;102(6):2009-18.

45. Jaquet $P$, Saveanu A, Gunz G, Fina F, Zamora AJ, Grino M, et al. Human somatostatin receptor subtypes in acromegaly: distinct patterns of messenger ribonucleic acid expression and hormone suppression identify different tumoral phenotypes. J Clin Endocrinol Metab. 2000;85(2):781-92.

46. Hofland LJ, van der Hoek J, van Koetsveld PM, de Herder WW, Waaijers M, Sprij-Mooij D, et al. The novel somatostatin analog SOM230 is a potent inhibitor of hormone release by growth hormone- and prolactin-secreting pituitary adenomas in vitro. $\mathrm{J}$ Clin Endocrinol Metab. 2004;89(4):1577-85.

47. Muhammad A, Coopmans EC, Gatto F, Franck SE, Janssen JAMJL, van der Lely AJ, et al. Pasireotide Responsiveness in Acromegaly Is Mainly Driven by Somatostatin Receptor Subtype 2 Expression. J Clin Endocrinol Metab. 2019;104(3):915-24.

48. Muhammad A, van der Lely AJ, Delhanty PJD, Dallenga AHG, Haitsma IK, Janssen JAMJL, et al. Efficacy and Safety of
Switching to Pasireotide in Patients With Acromegaly Controlled With Pegvisomant and First-Generation Somatostatin Analogues (PAPE Study). J Clin Endocrinol Metab. 2018;103(2):586-95.

49. Muhammad A, Coopmans EC, Delhanty PJD, Dallenga AHG, Haitsma IK, Janssen JAMJL, et al. Efficacy and Safety of switching to Pasireotide in Acromegaly Patients controlled with Pegvisomant and Somatostatin Analogues: PAPE extension study. Eur J Endocrinol. 2018;179(5):269-77.

50. Cuevas-Ramos D, Carmichael JD, Cooper O, Bonert VS, Gertych A, Mamelak AN, et al. A structural and functional acromegaly classification. J Clin Endocrinol Metab. 2015;100(1):122-31.

51. Colao A, Pivonello R, Auriemma RS, Galdiero M, Savastano S, Lombardi G. Beneficial effect of dose escalation of octreotideLAR as first-line therapy in patients with acromegaly. Eur $\mathrm{J}$ Endocrinol. 2007;157(5):579-87.

52. Caron PJ, Bevan JS, Petersenn S, Flanagan D, Tabarin A, Prévost G, et al.Tumor shrinkage with lanreotide Autogel $120 \mathrm{mg}$ as primary therapy in acromegaly: results of a prospective multicenter clinical trial. J Clin Endocrinol Metab. 2014;99(4):1282-90.

53. An JJ, Cho SR, Jeong DW, Park KW, Ahn YS, Baik JH. Antiproliferative effects and cell death mediated by two isoforms of dopamine D2 receptors in pituitary tumor cells. Mol Cell Endocrinol. 2003;206(1-2):49-62.

54. Vilar L, Azevedo MF, Naves LA, Casulari LA, Albuquerque JL, Montenegro RM, et al. Role of the addition of cabergoline to the management of acromegalic patients resistant to longterm treatment with octreotide LAR. Pituitary. 2011;14(2):148-56.

55. Bianchi A, Valentini F, luorio R, Poggi M, Baldelli R, Passeri M, et al. Long-term treatment of somatostatin analog-refractory growth hormone-secreting pituitary tumors with pegvisomant alone or combined with long-acting somatostatin analogs: a retrospective analysis of clinical practice and outcomes. J Exp Clin Cancer Res. 2013;32:40.

56. Neggers SJ, de Herder WW, Janssen JA, Feelders RA, van der Lely AJ. Combined treatment for acromegaly with long-acting somatostatin analogs and pegvisomant: long-term safety for up to 4.5 years (median 2.2 years) of follow-up in 86 patients. Eur $J$ Endocrinol. 2009;160(4):529-33.

57. Coopmans EC, van der Lely AJ, Schneiders JJ, Neggers S. Potential antitumour activity of pasireotide on pituitary tumours in acromegaly. Lancet Diabetes Endocrinol. 2019;7(6):425-6.

58. Coopmans EC, van der Lely AJ, Schneiders JJ, Neggers SJCMM. Shrinkage of pituitary adenomas with pasireotide \&\#x2013; Authors' reply. The Lancet Diabetes \& Endocrinology 2019; 7(7): 509-10.

59. Cozzolino A, Feola T, Simonelli I, Puliani G, Pozza C, Giannetta E, et al. Somatostatin Analogs and Glucose Metabolism in Acromegaly: A Meta-analysis of Prospective Interventional Studies. J Clin Endocrinol Metab. 2018;103(3):2089-99.

60. Buchfelder M, van der Lely AJ, Biller BMK, Webb SM, Brue T, Strasburger CJ, et al. Long-term treatment with pegvisomant: observations from 2090 acromegaly patients in ACROSTUDY. Eur J Endocrinol. 2018;179(6):419-27.

61. Bonert VS, Kennedy L, Petersenn S, Barkan A, Carmichael J, Melmed S. Lipodystrophy in patients with acromegaly receiving pegvisomant. J Clin Endocrinol Metab. 2008;93(9):3515-8.

62. Caputo C, Prior D, Inder WJ. The Third Case of CabergolineAssociated Valvulopathy: The Value of Routine Cardiovascular Examination for Screening. J Endocr Soc. 2018;2(8):965-9.

63. Vallette S, Serri K, Rivera J, Santagata P, Delorme S, Garfield $\mathrm{N}$, et al. Long-term cabergoline therapy is not associated with valvular heart disease in patients with prolactinomas. Pituitary. 2009;12(3):153-7.

64. Schmid HA, Brue T, Colao A, Gadelha MR, Shimon I, Kapur K, et al. Effect of pasireotide on glucose- and growth hormone-related biomarkers in patients with inadequately controlled acromegaly. Endocrine. 2016;53(1):210-9. 